\title{
Combined use of off-pump techniques and a sutureless proximal aortic anastomotic device reduces cerebral microemboli generation during coronary artery bypass grafting
}

John E. Scarborough, $\mathrm{MD}^{\mathrm{a}}$

William White, MPH

Frantz E. Derilus, BS ${ }^{\mathrm{b}}$

Joseph P. Mathew, $M D^{b}$

Mark F. Newman, $M D^{b}$

Kevin P. Landolfo, $\mathrm{MD}^{\mathrm{a}}$

The Neurologic Outcome

Research Group (NORG)

From the Departments of Surgery a and Anesthesiology, ${ }^{\text {b Duke University Medical }}$ Center, Durham, NC.

Supported in part by a grant from St Jude Medical, Inc, St Paul, Minn.

Received for publication April 29, 2002; revisions requested June 14, 2002; revisions received Dec 4, 2002; accepted for publication Jan 14, 2003.

Address for reprints: Kevin P. Landolfo, MD, Duke University Medical Center, Box 3675, Durham, NC 27710 (E-mail: Lando001@mc.duke.edu).

J Thorac Cardiovasc Surg 2003;126:1561-7

Copyright $\odot 2003$ by The American Association for Thoracic Surgery

$0022-5223 / 2003 \$ 30.00+0$

doi:10.1016/S0022-5223(03)01039-0
Objective: Intraoperative cerebral microemboli are associated with the development of postoperative stroke and neurocognitive decline in patients undergoing coronary artery bypass grafting. Although cardiopulmonary bypass is responsible for the generation of a significant number of such emboli, the elimination of cardiopulmonary bypass alone has not been conclusively shown to improve neurocognitive outcome. The current study was performed to determine the effects of combined off-pump coronary artery bypass grafting and sutureless proximal aortic anastomotic techniques on the generation of intraoperative cerebral microemboli compared with standard coronary artery bypass grafting techniques of cardiopulmonary bypass and hand-sewn proximal anastomoses.

Methods: Fifty-three patients underwent off-pump coronary artery bypass grafting by using the sutureless Symmetry aortic connector device (St Jude Medical, St Paul, Minn) for all proximal anastomoses. Eighteen of these patients received intraoperative transcranial Doppler ultrasonography to determine right- and left-sided cerebral microembolic counts. These results were compared with those obtained from a similar group of 17 patients undergoing standard coronary artery bypass grafting, in whom cardiopulmonary bypass and hand-sewn proximal anastomoses were used.

Results: Our use of the proximal anastomotic device in patients undergoing coronary artery bypass grafting was safe, with no aortic complications, postoperative strokes, or in-hospital deaths. Microembolic counts to both the right and left cerebral circulation were significantly reduced in the patients undergoing off-pump coronary artery bypass grafting (right $=21.9 \pm 20.7$ emboli, left $=24.9 \pm 19.2$ emboli) compared with those in patients undergoing standard coronary artery bypass grafting $($ right $=181.6 \pm 85.3$, left $=189.9 \pm 60.401, P<.0001)$.

Conclusions: Our use of a sutureless proximal anastomotic device during off-pump coronary artery bypass grafting is safe and significantly decreases cerebral microembolism when compared with standard coronary artery bypass grafting with cardiopulmonary bypass and hand-sewn anastomoses. Long-term follow-up is needed to determine the effects of this technical strategy on neurocognitive outcome. 


\section{$\mathbf{N}$}

eurologic dysfunction is a major contributor to postoperative morbidity and mortality after coronary artery bypass grafting (CABG). The incidence of focal neurologic impairment after this procedure has ranged from $1 \%$ to $5 \%$ in the literature. In addition to clinical stroke, the potential for milder neurocognitive dysfunction after cardiac surgery is being increasingly recognized. An inverse temporal relationship between the time of the operation and the manifestations of neuropsychologic decline has been suspected on the basis of initial outcome studies, with the highest incidence of this complication occurring at discharge $50 \%$ $85 \%) .{ }^{1,2}$ However, a recent article has shown the incidence of neurocognitive deterioration after coronary surgery to be as high as $42 \%$ five years after the procedure, indicating that this type of dysfunction might persist or even progress long after the immediate postoperative period. ${ }^{3}$ Concerted efforts to reduce the incidence of this complication are important because even mild impairment in neuropsychologic functioning can have significant effects on the quality of life of the patient. ${ }^{4}$

The association between cardiopulmonary bypass (CPB) support during coronary artery surgery and the development of postoperative neurologic dysfunction is well established. ${ }^{5-7} \mathrm{~A}$ correlation between the number of emboli during $\mathrm{CPB}$ and the incidence of postoperative neurocognitive deterioration has also been demonstrated. ${ }^{8}$ Transcranial Doppler ultrasound (TCDU) studies demonstrate significant embolic load during several intraoperative events. Ascending aortic cannulation and crossclamping, with subsequent release of atheromatous debris, are thought to be major sources of these emboli. ${ }^{9-14}$ Previous reports have also demonstrated that the return of shed blood returned directly to the patient through cardiotomy suction might produce microembolization. Such blood return through cardiotomy suction has been purported to cause an increase in small capillary arterial dilatations, which represent acellular lipoid deposits in the afferent microvasculature of the brain and are suspected of causing central nervous system injury after CPB. ${ }^{15,16}$ Off-pump CABG (OPCAB) holds promise as a potential method by which the frequency of intraoperative cerebral microembolization, and therefore postoperative neurologic dysfunction, can be reduced. Preliminary investigations show that off-pump coronary bypass procedures are associated with significantly fewer cerebral embolic events than when performed with extracorporeal circulation. ${ }^{17-19}$ However, the risk of cerebral embolus generation and thus postoperative neurologic dysfunction is not eliminated simply by removing extracorporeal support from coronary artery bypass procedures. Because atheromatous emboli have been shown to result from ascending aortic crossclamping during proximal aorta-vein graft anastomo- ses, compromise of the cerebral microcirculation remains a possibility, even during off-pump coronary surgery. ${ }^{20}$ This might explain why investigators have not been able to show uniform improvement in neurocognitive outcome in patients undergoing off-pump procedures. ${ }^{21-23}$

The optimal strategy for avoiding intraoperative cerebral embolic events and, subsequently, postoperative neurologic dysfunction should therefore include both the elimination of $\mathrm{CPB}$ and the minimization of intraoperative ascending aortic manipulation. We performed the present study to assess the effects of such a combined strategy on the frequency of intracerebral microembolic events during CABG. To do this, we compared the number of such embolic events during coronary bypass procedures by using either offpump surgery in combination with a sutureless proximal anastomotic device or standard CABG with CPB and traditional hand-sewn anastomoses with aortic crossclamping. We hypothesized that, when compared with standard $\mathrm{CABG}$, a procedure that minimizes aortic manipulation by eliminating both CPB and aortic crossclamping, the offpump would result in fewer intraoperative cerebral microembolic events.

\section{Materials and Methods}

\section{Patient Enrollment}

After receiving institutional review board approval for the following study protocol, 53 patients underwent OPCAB procedures with the Symmetry proximal aortic anastomotic device (St Jude Medical, St Paul, Minn) during the period between June 2001 and December 2001. Of these patients, 21 provided written preoperative consent for intraoperative TCDU monitoring (OPCAB group). A separate group of 26 patients undergoing standard CABG with $\mathrm{CPB}$ and freehand proximal anastomoses during the same time period also consented to intraoperative TCDU (S-CABG group). All coronary bypass procedures were performed by the same surgeon (K.P.L.). The exclusion criteria for enrollment into the study included patients undergoing multiple arterial grafting and patients with venous conduits that measured less than $4.0 \mathrm{~mm}$ in outer diameter.

\section{Transcranial Doppler Technique}

In 21 patients in the OPCAB group and 26 patients in the S-CABG group, intraoperative emboli detection was performed by using two 2-MHz pulse-wave Doppler probes fixed on a special headset and connected to a DWL Multiflow transcranial Doppler (TCD) machine (DWL GmbH, Sipplingen, Germany). The parameters used for the Multiflow TCD were software version 8.27I, scale between -100 and $+100 \mathrm{~cm} / \mathrm{s}$, sample volume of $10 \mathrm{~mm}$, 64-point fast Fourier transform (FFT), FFT length of $2.2 \mathrm{~ms}$, FFT overlap of at least $50 \%$, and high-pass filter set at $100 \mathrm{~Hz}$. The separation between the 2 sample volumes was $5 \mathrm{~mm}$ (dual-gate TCD), and the pulse repetition frequency was set at $6000 \mathrm{~Hz}$. TCD was performed from the time of skin incision until wound closure. Intraoperatively, adjustments were made to obtain the strongest signal possible. These signals were then recorded continuously on a hard drive for offline analysis. Postoperatively, the data for each patient 
were analyzed by a member of our team (F.D.) who was blinded to the patient's group assignment. On the basis of prior experience and a desire to minimize artifacts, we selected an intensity detection of 17 decibels. Artifact rejection was also enhanced by using the dual-gate TCD technique, wherein a Doppler signal had to be detected at 2 different depths to be recognized as a true embolus. After waveform analysis was performed, each signal was further assessed for sound characteristics indicative of true embolization.

\section{Patient Management}

OPCAB procedures. Anesthesia was established with midazolam, fentanyl, and pancuronium and maintained with isoflurane. All patients were monitored with arterial and pulmonary artery catheters. During cardiac displacement, blood pressure was maintained within a mean arterial pressure range of 60 to $70 \mathrm{~mm} \mathrm{Hg}$, with hemodynamics adjusted by using adrenergic agents when indicated to ensure a cardiac index of greater than $2.0 \mathrm{~L} \cdot \mathrm{min}^{-1}$. $\mathrm{m}^{-2}$. Coronary grafting was performed by using one of the commercially available stabilization devices (Medtronic Inc, Minneapolis, Minn; Genzyme Inc, Cambridge, Mass; or Guidant Inc, Santa Clara, Calif) The patient's temperature was maintained as close to normal $\left(37^{\circ} \mathrm{C}\right)$ as possible by using heated fluids and forced-air warming.

All saphenous vein-aortic anastomoses were performed by using the US Food and Drug Administration-approved Symmetry Bypass System device. On completion of device deployment, the anastomosis was inspected for leaks. If present, the leak was closed with 7-0 Prolene sutures. Aortic clamping was not performed at any time during the procedure.

$S$-CABG procedures. Anesthesia was established as described previously. The perfusion apparatus consisted of the Cobe CML membrane oxygenator (Cobe Laboratories, Lakewood, Colo), the Sarns 7000 max pump (3M Inc, Ann Arbor, Mich), and the Pall SP3840 arterial line filter (Pall Biomedical Products Co, Glencove, NY). Perfusion was maintained at pump flow rates of 2.0 to $2.4 \mathrm{~L}$ $\cdot \min ^{-1} \cdot \mathrm{m}^{-2}$ throughout CPB. The pump was primed with crystalloid, and serial hematocrit levels were maintained at greater than or equal to 0.18 with packed red blood cell supplementation as necessary. Arterial blood gases were followed every 15 to 30 minutes to maintain arterial carbon dioxide partial pressures of 35 to $40 \mathrm{~mm} \mathrm{Hg}$ and oxygen partial pressures of 150 to $250 \mathrm{~mm} \mathrm{Hg}$. Mild hypothermia was used during $\mathrm{CPB}$, with the patient cooled to $32^{\circ} \mathrm{C}$ to $34^{\circ} \mathrm{C}$. After completion of the coronary anastomoses, the patient was gradually rewarmed to a nasopharyngeal temperature of $37^{\circ} \mathrm{C}$ in standard fashion.

In the S-CABG group all saphenous vein-aortic anastomoses were performed by using traditional freehand techniques. Aortic cannulation and crossclamping was performed in all patients as part of the CPB protocol, with the crossclamp being replaced by a partial clamp for performance of the proximal anastomoses.

\section{Statistical Methods}

Age and ejection fraction were determined for patients in the OPCAB and S-CABG groups and compared by using independent-samples 2-tailed $t$ tests. Sex and the number of bypass grafts received were also compared between the 2 groups by using Fisher exact tests. Once the 2 groups were assessed for similarity in this manner, a comparison of both right-sided and left-sided cerebral
TABLE 1. Demographic profile of the OPCAB group in which proximal aortic anastomoses were performed with a sutureless anastomotic device

\begin{tabular}{lc}
\hline & $\begin{array}{c}\text { OPCAB group with } \\
\text { sutureless anastomotic } \\
\text { device }\end{array}$ \\
\hline No. of patients & 53 \\
Age (y) & $64.5 \pm 10.0$ \\
Race (white) & $87 \%$ \\
Sex (male) & $56.7 \%$ \\
Preoperative ejection fraction & $49.0 \pm 12.0$ \\
Mean no. of total grafts & $2.9 \pm 0.9$ \\
Mean no. of saphenous venous grafts & $2.0 \pm 0.8$ \\
Intraoperative proximal anastomotic & $1.8 \%$ \\
$\quad$ revisions & $148 \pm 57$ \\
Length of follow-up (d) & $6.2 \pm 4.3$ \\
Length of stay (d) & $1.8 \%$ \\
Postoperative take backs for bleeding & $0 \%$ \\
Postoperative stroke & $0 \%$ \\
30-day mortality & \\
\hline
\end{tabular}

microemboli counts between the groups was made by using the Wilcoxon 2-sample rank sum test to allow for the nonnormality of the distribution.

\section{Results}

\section{Demographics}

Fifty-three consecutive patients from June 2001 to December 2001 who met the study criteria underwent OPCAB with the proximal sutureless anastomotic device for all aorta-saphenous vein anastomoses. The demographic profile of these patients is provided in Table 1. Of these patients, 21 consented to intraoperative TCDU monitoring. Mean age, number of grafts, and preoperative ejection fraction of this subset of patients were similar to those of the entire sample of OPCAB group as a whole. When the demographic variables of the OPCAB group were compared with those of the S-CABG group, no significant difference was found in mean age, preoperative ejection fraction, or total number of bypass grafts received (Table 2). The 2 groups did differ significantly with respect to sex distribution, with female patients comprising a relatively greater proportion of the OPCAB group than the S-CABG group.

\section{OPCAB Group}

Fifty-three total patients underwent OPCAB with the sutureless anastomotic device for all proximal anastomoses (Table 1). A total of 106 proximal anastomoses, or $2.0 \pm$ 0.8 per patient, were performed. Each of these proximal anastomoses was performed with the sutureless device. Intraoperatively, there were no aortic complications, and no patient required aortic clamping. Two proximal anastomoses required intraoperative revision because of small leaks at the anastomotic site after device deployment. There were 
TABLE 2. Comparison of demographic variables between patients in the OPCAB and S-CABG groups who underwent intraoperative TCDV

\begin{tabular}{lccc}
\hline & OPCAB group & S-CABG group & $\begin{array}{c}\text { Alpha } \\
\text { value }\end{array}$ \\
\hline No. of patients & 21 & 26 & \\
Age (y) & $62.9 \pm 12.2$ & $60.1 \pm 9.3$ & $.3813^{*}$ \\
$\begin{array}{l}\text { Sex (male) } \\
\text { Preoperative ejection } \\
\quad\end{array}$ & $55.8 \pm 10.1$ & $52.5 \pm 10.0$ & $.2824^{*}$ \\
$\begin{array}{l}\text { Meaction no. of total grafts } \\
\text { Mean no }\end{array}$ & $3.1 \pm 0.7$ & $3.3 \pm$ & $.5066^{*}$ \\
\hline${ }^{*} P$ value standard $t$ test. & & & \\
$\dagger P$ value with Fisher exact test. & &
\end{tabular}

no instances, however, in which the device failed to deploy properly. Postoperatively, there were no strokes or in-hospital deaths. One (1.8\%) patient required reoperation for postoperative bleeding. On take back, a small branch of the left internal thoracic artery was found to be the source of the bleeding, with both of that patient's proximal anastomoses appearing hemostatic. Mean length of stay for the OPCAB group was $6.2 \pm 4.3$ days. After a mean follow-up of $148 \pm$ 57 days, there were no procedure-related rehospitalizations or deaths in the OPCAB group. In the S-CABG group there were no strokes, in-hospital deaths or reoperations for bleeding. Two patients in this group required rehospitalization, one for mediastinitis and the other for recurrent myocardial infarction caused by kinking of the left internal thoracic arterial graft.

\section{Cerebral Microembolic Counts}

A total of 21 patients in the OPCAB group and 26 patients in the S-CABG group received continuous intraoperative TCDU monitoring. Successful monitoring was achieved in 18 of the 21 patients in the OPCAB group in whom TCD was attempted. Similarly, 17 of the 26 patients in the SCABG group were also successfully monitored. The primary reasons for unsuccessful monitoring were the inability to obtain an adequate ultrasound signal and the inability to maintain the signal throughout the entire period.

Embolic events were monitored and recorded separately for the right and left cerebral circulations. Mean and median right- and left-sided counts were calculated and compared between groups (Figure 1). Because emboli counts were not normally distributed, comparisons of counts between the 2 groups were made by using the Wilcoxon 2-sample rank sum test. Patients in the OPCAB group had significantly fewer left-sided cerebral embolic events intraoperatively (mean, $24.9 \pm 19.2$; median, 26.0) than patients in the S-CABG group (mean, $189.9 \pm 60.4$; median, 180.0; $P<$ .0001). A similarly significant difference in embolic counts was also noted in the right cerebral circulation (mean of $21.9 \pm 20.7$ and median of 18.0 for the OPCAB group vs mean of $181.6 \pm 85.3$ and median of 173.0 for the S-CABG group, $P<.0001)$.

The frequency of intraoperative embolic events during specific time periods was also analyzed. In the OPCAB group $100 \%$ microembolic events occurred during sutureless anastomotic device insertion and deployment. No emboli were detected when the heart was displaced for performance of the distal anastomoses. In the S-CABG group $30.0 \%$ (mean, $51.2 \pm 48.7$ ) of the microemboli occurred during aortic cannulation to aortic crossclamp application, $40.1 \%$ (mean, $74.4 \pm 52.1$ ) occurred from aortic crossclamp application to removal, $23.9 \%$ (mean $43.7 \pm 26.0$ ) occurred from aortic crossclamp removal to aortic decannulation, and $6.0 \%$ occurred from aortic decannulation to chest closure. A similar temporal distribution of embolic events was found for the right cerebral circulation of the patients in the S-CABG group.

\section{Discussion}

We performed OPCAB in 53 patients using a sutureless anastomotic device for all aorta-saphenous vein graft anastomoses. The use of a sutureless anastomotic technique for the proximal anastomoses was safe, with no aortic complications occurring during a total of 106 such anastomoses. Persistent leakage from the anastomosis after device deployment did occur in 2 cases, but these leakage sites were easily repaired with only a single supplemental suture per anastomosis. The causes of these leaks are unknown, but they were not related to any technical difficulties with the device or to crowding of the proximal anastomoses on the aorta when more than one proximal sutureless graft was performed. Postoperatively, there was one reoperation for bleeding, with the source of bleeding identified intraoperatively as a small branch of the left internal thoracic artery. There were no postoperative strokes or in-hospital deaths. There was one late death, the cause of which was unrelated to the patient's OPCAB procedure.

A subset of patients in the OPCAB group underwent intraoperative TCDU to quantitate the number of microemboli traversing the cerebral circulation. We compared the results from this subset of patients with those obtained from a group of patients undergoing standard CABG in whom both CPB and hand-sewn proximal anastomotic techniques were used. The patients in the S-CABG group were similar to those in the OPCAB subset in terms of age, preoperative ejection fraction, and the number of grafts received, although the S-CABG group had a significantly larger proportion of male patients. We found that the number of microemboli generated during $\mathrm{CABG}$ was more than 7-fold greater in the $\mathrm{S}-\mathrm{CABG}$ group than in the OPCAB group. To our knowledge, this is the first such demonstration that the combined use of off-pump surgery and sutureless proximal anastomotic devices is associated with a significant reduc- 


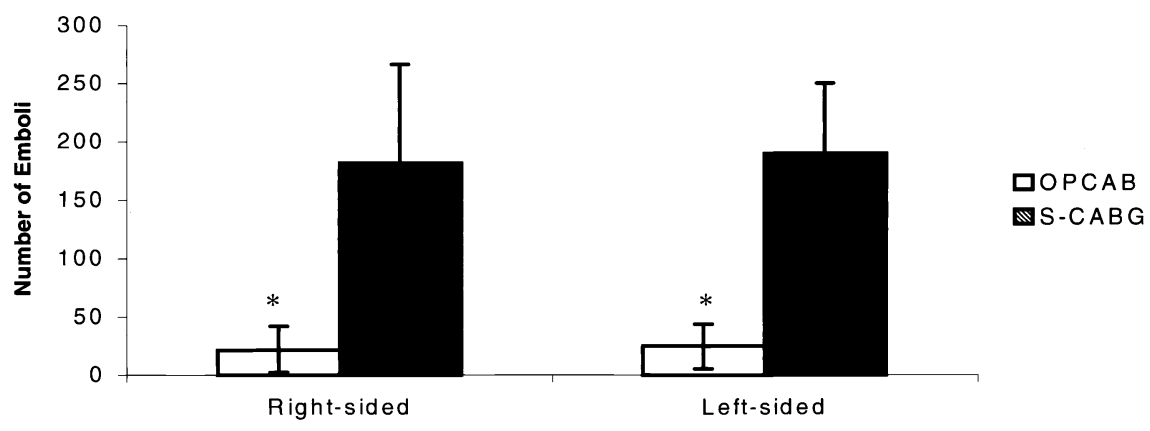

Figure 1. Comparison of mean cerebral embolic counts between the OPCAB and S-CABG groups. ${ }^{*} P<.0001$ (vs S-CABG group) by using the Wilcoxon 2-sample rank sum test.

tion in cerebral microemboli generation when compared with that seen in standard CABG techniques.

The association between cerebral microemboli during CABG and the development of postoperative neurocognitive dysfunction is strong. Stump and colleagues ${ }^{8}$ performed a prospective study of 167 patients receiving neuropsychologic testing within 5 to 7 days after standard CABG. Continuous intraoperative TCDU was also performed in these patients. The authors found that the number of microemboli detected intraoperatively correlated highly with the development of postoperative neuropsychologic dysfunction. Specifically, $79 \%$ of patients with greater than 100 intraoperative embolic events had a neurocognitive deficit compared with $63 \%$ of patients who had fewer than 100 embolic events. Moreover, patients who did demonstrate postoperative neuropsychologic decline averaged twice as many embolic events during CABG as patients who did not have postoperative impairment. Pugsley and associates ${ }^{11}$ also examined neurocognitive outcome in 94 consecutive patients undergoing CABG but at 8 weeks postoperatively. In this study $43 \%$ of patients with intraoperative embolic counts of greater than 1000 experienced postoperative cognitive decline at 8 weeks compared with only $9 \%$ of patients with fewer than 200 events.

CPB is a significant source of cerebral microemboli during CABG. The aortic manipulation required for aortic cannulation and clamping appears to be one of the primary risk factors for cerebral embolism. In our study we found that the period during cannulation to crossclamp application resulted in approximately $30 \%$ of all microembolic events in the S-CABG group, whereas the period involving crossclamp application and removal accounted for $40 \%$ of such events. In a study of 196 patients undergoing CABG with $\mathrm{CPB}$, Stump and colleagues ${ }^{14}$ used intraoperative TCDU to determine when cerebral microemboli occurred during the procedure. They found that periods of aortic cannulation and ascending aortic clamping during CPB accounted for more than $40 \%$ of intraoperative cerebral microembolic events. Cardiotomy suctioning is another source of cerebral microemboli during $\mathrm{CPB}$, producing acellular lipoid deposits that have been shown to lead to small capillary arterial dilatations within the afferent cerebral microvasculature. Such dilatations are believed to represent foci of central nervous system injury that ultimately result in neurocognitive dysfunction postoperatively. ${ }^{15,16}$ By eliminating the use of CPB during coronary bypass surgery, it is thought that many of these atheromatous and lipoid embolic events can be avoided. Several groups of investigators have therefore sought to determine the effect of off-pump coronary surgery, in which CPB is not used, on intraoperative emboli counts. Watters and colleagues ${ }^{18}$ performed a study of 20 patients undergoing multivessel CABG. Ten of these patients received standard $\mathrm{CABG}$ with $\mathrm{CPB}$, whereas the other 10 patients received OPCAB. All patients were monitored with TCDU from the time of pericardiotomy until $10 \mathrm{~min}$ utes after the last aortic instrumentation. The mean microemboli count in the patients in which CPB was used was 79 compared with only 3 in patients undergoing off-pump surgery. None of the patients in this small study had gross neurologic dysfunction postoperatively. A similar retrospective review of 40 patients by Bowles and coworkers ${ }^{17}$ demonstrated that the elimination of CPB from the coronary bypass grafting procedure significantly reduced the mean intraoperative cerebral emboli count from 1766 to 27.

Although the use of OPCAB does appear to significantly reduce the frequency of cerebral microemboli, it is not clear whether this reduction in emboli counts translates into improved postoperative neurocognitive function. Diegeler and associates $^{21}$ performed intraoperative TCDU and postoperative neurocognitive testing in a total of 40 patients undergoing CABG. Twenty of these patients underwent OPCAB, and the other 20 underwent CPB. The off-pump group had significantly fewer intraoperative cerebral microemboli and significantly less cognitive impairment in the early postoperative period. In another study of 60 patients undergoing CABG, however, Lloyd and colleagues ${ }^{22}$ found no significant difference in neurocognitive function at 12 weeks postoperatively between patients who underwent OPCAB 
and those who received conventional CABG with CPB. Moreover, a recent prospective trial of 281 patients randomized to either OPCAB or conventional CABG also failed to show any statistically significant difference in the incidence of neurocognitive deterioration at 12 months postoperatively. ${ }^{23}$

Thus it appears that simply eliminating the use of $\mathrm{CPB}$ by performing CABG off pump might not prevent postoperative neurocognitive deterioration. This lack of outcome benefit might be due to the fact that aortic clamping and the embolic sequelae of such clamping are still required during off-pump surgery to perform proximal aortic anastomoses. In our S-CABG group, such instrumentation accounted for up to $40 \%$ of microemboli detected. However, the advent of sutureless anastomotic devices now makes it possible to perform proximal aorta-saphenous vein graft anastomoses without aortic clamping of any type. By combining offpump surgery with sutureless proximal aortic anastomotic techniques, thus minimizing the degree of intraoperative aortic manipulation, it might be possible to further reduce the number of cerebral embolic events to such a level that the incidence of postoperative neurocognitive deterioration is also minimized. In the current study we have shown that such a strategy does in fact result in fewer embolic events than conventional CABG techniques. Although sutureless anastomotic device deployment did cause embolic generation in the OPCAB group, the mean number of emboli generated was considerably lower than the number of emboli that occurred in the S-CABG group during aortic cannulation, crossclamp application, and crossclamp removal. Conversely, because aortic crossclamping is required during $\mathrm{CPB}$ and accounts for the majority of emboli generated during this procedure, there appears to be no benefit to using a sutureless proximal anastomotic device during standard CABG.

A major limitation of our study was our inability to assess the individual contributions of off-pump bypass grafting and sutureless proximal anastomoses to the reduction in cerebral embolic events. Specifically, we did not include a group of patients in whom OPCAB was performed with aortic crossclamping and hand-sewn proximal anastomoses. Such a comparison would enable us to further delineate the benefits of sutureless proximal anastomoses with regard to microemboli generation during OPCAB. A larger study population would be required to demonstrate a difference in cerebral microembolic events between OPCAB performed with aortic crossclamping and hand-sewn anastomoses versus no crossclamping and sutureless anastomoses. Unfortunately, we were not able to include a study population of this size. However, the findings of the current study are still relevant because they show, for the first time, that minimizing aortic intraoperative manipulation during CABG is associated with fewer cerebral emboli than standard CABG techniques. A second limitation of our study was that we did not assess postoperative neurocognitive outcomes. Although no patient from either group had postoperative stroke, prospective long-term follow-up with more sensitive and specific testing is required to determine neuropsychologic outcome. However, given the strong association between intraoperative cerebral microembolic events during $\mathrm{CABG}$ and the development of postoperative neurocognitive dysfunction, we believe that the ability to greatly reduce the occurrence of such embolic events by minimizing aortic manipulation will translate into improved neurocognitive outcome when examined prospectively in the future.

In summary, we have demonstrated, for the first time, that efforts to minimize aortic manipulation during $\mathrm{CABG}$ by eliminating $\mathrm{CPB}$ and by using a sutureless anastomotic device for all proximal aortic anastomoses results in significantly fewer intraoperative cerebral embolic events. Further investigation is warranted to determine the effects of such a technique on neurocognitive outcome.

\section{References}

1. Engleman DT, Cohn LH, Rizzo RJ. Incidence and predictors of TIAs and strokes following coronary artery bypass grafting: report and collective review. Heart Surg Forum. 1999;2:242-5.

2. Van Dijk D, Keizer AM, Diephuis JC, Durand C, Vos LJ, Hijman R. Neurocognitive dysfunction after coronary artery bypass surgery: a systematic review. J Thorac Cardiovasc Surg. 2000;120:632-9.

3. Newman MF, Kirchner JL, Phillips-Bute G, et al. Longitudinal assessment of neurocognitive function after coronary artery bypass surgery. $N$ Engl J Med. 2001;344:395-402.

4. Newman MF, Grocott HP, Mathew JP, et al. Report of the substudy assessing the impact of neurocognitive function on quality of life 5 years after cardiac surgery. Stroke. 2001;32:2874-81.

5. Newman S, Smith P, Treasure T, Joseph EP, Harrison M. Acute neuropsychological consequences of coronary artery bypass surgery. Curr Psychol Res Rev. 1987;6:115-24.

6. Vingerhoets G, Van Nooten G, Vermassen F, De Soete G, Jannes C. Short-term and long-term neuropsychological consequences of cardiac surgery with extracorporeal circulation. Eur J Cardiothorac Surg. 1997;11:424-31.

7. Hammeke TA, Hastings JE. Neuropsychologic alterations after cardiac operations. J Thorac Cardiovasc Surg. 1998;96:326-31.

8. Stump DA, Tegeler CH, Rogers AT, et al. Neuropsychological deficits are associated with the number of emboli detected during cardiac surgery. Stroke. 1993;24:509-16.

9. Hammon JW, Stump DA, Kon ND, et al. Risk factors and solutions for the development of neurobehavioral changes after coronary artery bypass grafting. Ann Thorac Surg. 1997;63:1613-8.

10. Clark RE, Brillman J, Davis DA, Lovell MR, Price TR, Magovern GJ. Microemboli during coronary artery bypass grafting. Genesis and effect on outcome. J Thorac Cardiovasc Surg. 1995;109:249-58.

11. Pugsley W, Klinger L, Paschalis C, Treasure T, Harrison M, Newman $\mathrm{S}$. The impact of microemboli during cardiopulmonary bypass on neuropsychological functioning. Stroke. 1994;25:1393-9.

12. Vaage J, Jensen U, Ericsson A. Neurologic injury in cardiac surgery: aortic atherosclerosis emerges as the single most important risk factor. Scand Cardiovasc J. 2000;34:550-7.

13. Borger MA, Ivanov J, Weisel RD, Rao V, Peniston CM. Stroke during coronary bypass surgery: principal role of cerebral macroemboli. Eur J Cardiothorac Surg. 2001;19:627-32.

14. Stump DA, Rogers AT, Kon ND, et al. When emboli occur during coronary artery bypass graft surgery [abstract]. Anesthesiology. 1993; 79:A49. 
15. Brooker RF, Brown WR, Moody DM, et al. Cardiotomy suction: a major source of brain lipid emboli during cardiopulmonary bypass. Ann Thorac Surg. 1998;65:1651-5.

16. Challa VR, Moody DM, Troost BT. Brain embolic phenomena associated with cardiopulmonary bypass. J Neurol Sci. 1993;117:224-31.

17. Bowles BJ, Lee JD, Dang CR, et al. Coronary artery bypass performed without the use of cardiopulmonary bypass is associated with reduced cerebral microemboli and improved clinical results. Chest. 2001;119: 25-30.

18. Watters MP, Cohen AM, Monk CR, Angelini GD, Ryder IG. Reduced cerebral embolic signals in beating heart coronary surgery detected by transcranial Doppler ultrasound. Br J Anaesth. 2000;84:629-31.

19. Bhasker Rao B, VanHimbergen D, Edmonds HL, et al. Evidence for improved cerebral function after minimally invasive bypass surgery. J Card Surg. 1998;13:27-31.

20. Harringer W. Capture of particulate emboli during cardiac procedures in which aortic-cross clamp is used. Ann Thorac Surg. 2000;70:1119-23.

21. Diegeler A, Hirsch R, Schneider F, et al. Neuromonitoring and neurocognitive outcome in off-pump versus conventional coronary bypass operation. Ann Thorac Surg. 2000;69:1162-6.

22. Lloyd CT, Ascione R, Underwood MJ, Gardner F, Black A, Angelini GD. Serum S-100 protein release and neuropsychologic outcome during coronary revascularization on the beating heart: a prospective randomized study. J Thorac Cardiovasc Surg. 2000;119:148-54.

23. Van Dijk D, Jansen EW, Hijman R, et al. Cognitive outcome after off-pump and on-pump coronary artery bypass graft surgery: a randomized trial. JAMA. 2002;287:1405-12.

\section{Appendix 1. Neurologic Outcome Research Group (NORG) of the Duke Heart Center.}

Director: Joseph P. Mathew, MD

Codirector: James A. Blumenthal, $\mathrm{PhD}$
Anesthesiology: John V. Booth, MD; Hilary P. Grocott, MD; Steven E. Hill, MD; Joseph P. Mathew, MD; Mark F. Newman, MD, J. G. Reves, MD; Debra A. Schwinn, MD; Mark StaffordSmith, MD; David Warner, MD; Bonita L. Funk, RN; E. D. Derilus, BS; Jason Hawkins, RN, BSN; I. Lee McClurkin, BA, RN; Terri Moore, BA; Chonna Campbell, BS; Amanda Cheek, AS; Roger L. Hall, AAS; Tanya Kagarise, BS; Jerry L. Kirchner, BS; Satarah Latiker, BS; Erich Lauff, BA; Charles R. Peters, MA; Meredith Prince; Joe Russell, RN; Debra L. Whiteheart, BS; Regina DeLacy, BA; William Hansley, BS; Yvonne M. Connelly, MA, MPH; Barbara Phillips-Bute, PhD; William D. White, MPH

Behavioral Medicine: Michael A. Babyak, PhD; James A. Blumenthal, $\mathrm{PhD}$

Cardiology: Daniel B. Mark, MD, MPH; Michael H. Sketch, Jr, MD

Neurology: Carmelo Graffagnino, MD; Daniel T. Laskowitz, MD; John R. Lynch, MD; Ann M. Saunders, PhD; Warren J. Strittmatter, MD; Kathleen A. Welsh-Bohmer, PhD

Pathology: Ellen Bennett, $\mathrm{PhD}$

Perfusion Services: Greg Smigla, BS, CCP; Ian Shearer, BS, CCP

Surgery: Robert W. Anderson, MD; Thomas A. D'Amico, MD; R. Duane Davis, MD; Donald D. Glower, MD; R. David Harpole, MD; James Jaggers, MD; Robert H. Jones, MD; Kevin Landolfo, MD; James E. Lowe, MD; Robert H. Messier, MD; Carmelo Milano, MD; Peter K. Smith, MD; Eric M. Toloza, $\mathrm{MD}, \mathrm{PhD}$; Walter G. Wolfe, MD 